\title{
Levantamento de anticorpos anti-bartonella henselae em felinos domiciliados na cidade de São Paulo, estado de São Paulo e sua importância em saúde pública
}

\section{A survey of anti-bartonella henselae antibodies in domiciliated cats in the city of São Paulo, state of São Paulo and its importance in public health}

\author{
Valéria de Souza Loureiro, ${ }^{*}$ Mitika Hagiwara**
}

\begin{abstract}
Resumo
A Doença da Arranhadura do Gato (DAG) é uma zoonose transmitida pelos gatos que caracteriza-se por linfoadenopatia regional acompanhada por febre, anorexia e perda de peso. Em pacientes imunodeprimidos, como os aidéticos, o quadro evolui para outras formas, desde encefalopatias até para a Angiomatose e a Peliose Bacilares, de evolução fatal. Os felídeos, principalmente os gatos domésticos, são o reservatório do agente, a Bartonella henselae, restando confirmar a idade na qual eles estão mais aptos a transmitir a doença. Foram analisados 200 soros de felinos na cidade de São Paulo, estado de São Paulo, no período de janeiro de 1996 até dezembro de 1997 através da técnica da imunofluorescência indireta. A metade deles era saudável e a outra metade era composta por animais atendidos no Ambulatório do Hospital Veterinário da Universidade de São Paulo. Os animais foram divididos em 4 grupos baseados em sua faixa etária: animais de até 6 meses de idade, entre 7 e 12 meses, animais de mais de 1 ano até 2 anos e outros com mais de 2 anos. O objetivo foi avaliar a presença de anticorpos IgG anti- $B$ henselae nos quatro grupos de animais, bem como o encontro desses anticorpos e o sexo ou o estado de higidez dos felinos. Foi encontrada soropositividade de $16 \%$ para $B$. henselae e observou-se que o maior número de animais reagentes se encontrava na faixa etária de 7 a 12 meses, e que não houve diferença entre a soropositividade e os sexos, ou entre os animais hígidos ou doentes. Concluiu-se, assim, que a infecção nos felinos se dá nas faixas etárias mais jovens com o desenvolvimento de anticorpos humorais, que diminuem conforme a idade dos animais.
\end{abstract}

Palavras-chave: Bartonella henselae, imunofluorescência indireta, felinos.

\begin{abstract}
Cat Scratch Disease (CSD) is a human disease transmited by scratch or bite of asyntomatics cats and characterized by regional limphadenopaty with fever, anorexy and weigh loss. In immunosupressed patients, like AIDS patients, there are systemic clinical presentations (bacillary angiomatosis or bacillary splenits), gerally fatal. Domestic cats are the main reservoir of Bartonella henselae, the agent of CSD and this prevalence is evaluated by serological test. In the period from January 1996 to December 1997, two hundred sera samples of domestic cat from city of São Paulo were analized by using indirect imunofluorescence test. Fifty percent of the animals were clinically healthy and other half was comprised by felines attended at Veterinary Hospital - University of São Paulo estate of São Paulo - Brasil . Felines were divided in four groups according to their ages: animal up to six months old, between seven and twelve months old, between one and two years old, and older than two years old. We intended to evaluate the presence of IgG-Bartonella henselae antibodies in the four groups of animals, relationships between antibodis and gender, and health status of the felines, as well. Seropositivity of $16 \%$ was found for $B$. henselae. When the age was analyzed, the evidence that within the group between seven and twelve months of age, was significantly higher than the other groups. There were no diference between genders, or between health and sick animals. We concluded, that the infection of felines happens at younger age, due to development of humoral antibodies that decrease with the age of animals.
\end{abstract}

Keywords: Bartonella henselae, immunofluorescence, felines.

\section{Introdução}

A doença da arranhadura do gato (DAG) é uma importante zoonose transmitida ao homem através de mordedura ou arranhadura de felinos domésticos, ou mesmo através de pulgas (Ctenocephalides felis) previamente contaminadas (Chomel et al., 1996 e 2006). A doença é geralmente benigna, caracterizada em sua forma típica por linfoadenopatia regional, acompanhada por febre e sintomas gerais como anorexia e perda de peso (Drancourt et al., 1995).

\footnotetext{
Mestre em Clínica Médica pela Faculdade de Medicina Veterinária e Zootecnia - USP - Rua Aripuanã, 64, Planalto Paulista - São Paulo, SP. E-mail: valoureiro@ig.com.br.

** USP - Faculdade de Medicina Veterinária e Zootecnia - Departamento de Clínica Médica - São Paulo, SP.
} 
No homem a DAG se caracteriza pelo aparecimento de pequenas pápulas ou pústulas eritematosas 7 a 12 dias após uma arranhadura ou mordedura felina, e depois de uma ou duas semanas os linfonodos responsáveis pela drenagem dessa região se tornam edemaciados e abscedam, supurando em 10 a $30 \%$ dos pacientes. Geralmente se observam febre de intensidade moderada e mal estar geral com anorexia, cefaléia e cansaço. 0 processo dura de 2 a 4 meses e costuma ter involução espontânea dentro de 6 meses (Margileth et al., 1993, Amarri et al., 1995, Lamps, et al., 2004).

Em pacientes imunodeprimidos como nos casos de Aids, transplantados e sob tratamento de quimioterapia, o quadro pode evoluir para Angiomatose Bacilar ou para Peliose Bacilar caracterizados respectivamente por proliferação de pequenos vasos sanguíneos na pele e órgãos viscerais, ou pelo aparecimento de espaços múltiplos, dilatados e hemorrágicos nesses órgãos de evolução fatal (Tompkins et al., 1993; Welch et al.,1996).

O agente responsável por tal patologia foi identificado como Bartonella henselae, um bacilo gram-negativo, pequeno, pleomórfico, encontrado isolado ou em cadeias curtas em média com 0,6 a 3,0 mm de comprimento e de 0,3 a 1,0 mm de diâmetro (Arlet et al., 1990 e 1991; Brenner et al.,1991).

O gato doméstico é confirmadamente o reservatório da $B$. henselae, porém a maioria dos animais permanece assintomática (Kirkpatrick et al.,1989; Ueno et al.,1996).

A bacteremia inicia-se entre 6 e 15 dias após a inoculação intra venosa (IV) do agente e persiste em média por 10 a 16 semanas chegando a até 24 meses, de forma cíclica. Ela é seguida de perto pelo aumento do título de anticorpos IgG anti- $B$. henselae a partir de uma ou duas semanas. Os anticorpos atingem títulos próximos de 1024 a 8192 na terceira semana pós-inoculação, e então inicia-se uma queda constante até atingir títulos de 512 a 1281, que se mantém por até 6 semanas. A bacteremia diminui à medida que aumentam os títulos de anticorpos ( $\mathrm{lgG}$ ), os quais controlam a multiplicação bacteriana. Assim os níveis de $\lg G$ são considerados indicativos de infecção passada ou corrente por $B$. henselae, pois os anticorpos podem coexistir com bacteremia por longos períodos após a infecção. Animais expostos a segunda infecção não desenvolvem bacteremia, porém ocorre aumento dos níveis de lgG.

A prevalência dos anticorpos anti- $B$. henselae e o encontro de bacteremia diminuem com a idade do felino indicando que os animais devem adquirir a doença no primeiro ano de vida, especialmente à partir dos seis meses de vida, com queda inversamente proporcional à idade do animal (Greene et al.,1994; Regnery et al.,1996; Kordick et al.,1997 e 1998, Micolajczyk, Mg et al., 2000).

Para a pesquisa de anticorpos foi utilizada a técnica de imunofluorescência indireta (IFI), teste cuja sensibilidade e especificidade dependem da linha de corte, que define o título a partir do qual o resultado será positivo. A linha de corte 64 é utilizada pela maioria dos autores citados, e tem especificidade de $94 \%$ e sensibilidade de $88 \%$, porém nesse estudo utilizaremos a linha de corte de 100, segundo Raoult et al. (1994), cujo valor preditivo positivo é 68,2\% (Regnery et al.,1992; Dalton et al.,1995; Amerein et al.,1996, Bergmas et al., 1997; Zbinden et al.,1998).
Este trabalho tem por objetivo avaliar a magnitude da infecção por $B$. henselae nos felinos domésticos na cidade de São Paulo, estado de São Paulo, através da pesquisa de anticorpos por meio da reação de imunofluorescência indireta e sua relação com a idade dos animais infectados e seu estado de saúde, visando auxiliar na prevenção da doença na população humana.

\section{Material e métodos}

Foram avaliadas amostras de soros de 200 felinos domiciliados na cidade de São Paulo (estado de São Paulo), com idades de 1 mês a 3 anos, metade dos quais hígidos e a outra metade composta por animais atendidos no Ambulatório do Hospital Veterinário da Faculdade de Medicina Veterinária e Zootecnia - Universidade de São Paulo, a partir janeiro de 1996 até dezembro de 1997.

Eles foram divididos em quatro grupos segundo sua faixa etária: felinos entre 1 e 6 meses $(n=41)$, felinos entre 7 e 12 meses $(n=56)$, com mais de 1 ano até 2 anos $(n=55)$ e animais acima de 2 anos $(n=45)$. Tal amostragem foi estabelecida por conveniência dos pesquisadores.

A técnica de imunofluorescência indireta foi realizada segundo o Centro Nacional de Referência para Ricketsioses, em atividade na Faculdade de Medicina, Farmácia e Odontologia de La Timone, Marselha, França.

A cepa de Bartonella henselae foi semeada em placas de Agar Columbia com $5 \%$ de sangue de carneiro durante 15 dias, num total de 4 passagens, e então foram co-cultivadas com células Vero por 72 horas, sempre em estufa de $37^{\circ} \mathrm{C}$ em ambiente de CO2. O material resultante foi lavado com PBS pH 7,2 e centrifugado a $4^{\circ} \mathrm{C}$ durante 10 minutos a 5.500 rpm, por três vezes.

Na lâmina para IFI foram distribuídas, com auxílio de bico-depena, finas camadas de $B$. henselae secas ao ar em temperatura ambiente, e depois fixadas no álcool etílico por 10 minutos.

Os soros foram diluídos em meio tampão PBS pH 7,2 acrescido de leite a $3 \%$, em progressão aritmética de razão 2 , a partir de $1 / 25$ até $1 / 800$. Aproximadamente $40 \mathrm{ml}$ de cada diluição foram colocados sobre o antígeno, e a seguir a lâmina foi incubada a $37^{\circ} \mathrm{C}$ por 30 minutos em câmara úmida, lavada com solução PBS pH 7,2, imersa em solução PBS Tween por 10 minutos por 2 vezes e finalmente, imersa em água destilada por mais 5 minutos. Após a secagem da lâmina em estufa $37^{\circ} \mathrm{C}$, foram acrescentados $30 \mathrm{ml}$ do conjugado de cabra anti-lgG felino (diluído a 1/ 50 em PBS leite 3\% corado com Azul de Evans a $0,05 \%$ ) sobre o antígeno e então novamente incubada a $37^{\circ} \mathrm{C}$ por 30 minutos em câmara úmida, procedendo-se a seguir, à lavagem e as imersões, conforme descrito anteriormente.

À lâmina seca em estufa $37^{\circ} \mathrm{C}$ acrescentou-se uma gota de Fluoprep (glicerina tamponada - meio de conservação para imunofluorescência - Biomerieux) cobrindo-se com lamínula. A reação foi observada ao microscópio de epifluorescência Zeiss com objetiva de $40 \mathrm{X}$ e a leitura da lâmina foi feita baseada na intensidade de fluorescência, numa classificação de $0,+1,+2,+3$ até +4 , $(0$ a ausência total de fluorescência e +4 a visualização da $B$. henselae perfeitamente fluorescente). 
Considerou-se resultado positivo aquele igual ou superior à fluorescência de +3 , em diluição de $1 / 100$.

O teste estatístico utilizado foi o teste $Z$ para análise dos dados dos quatro grupos de felinos, comparando-se a proporção de animais soropositivos entre cada faixa etária, assim como avaliada a freqüência de soropositividade entre os grupos saudáveis e doentes, machos e fêmeas, para p d" 0,05 (cálculos com auxílio do programa SPSS for Windows release 6,0 ).

\section{Resultados}

Dentre os 200 felinos incluídos nesse estudo, os 100 animais hígidos e os 100 animais atendidos no Ambulatório do Hospital Veterinário da Faculdade de Medicina Veterinária e Zootecnia - USP, foram observados 32 reagentes à $B$. henselae, correspondendo a $16 \%$ da amostragem utilizada.

A maior freqüência dos reagentes conforme o título de anticorpos anti- $B$. henselae detectados através da reação IFI foi observada no grupo de animais da faixa etária de 7 a 12 meses, seguida pela faixa de 1a 6 meses. Observa-se diferença significativa entre os animais da faixa etária de 7 a 12 meses com os da faixa etária de $>1$ ano a 2 anos, e os de mais de 2 anos.

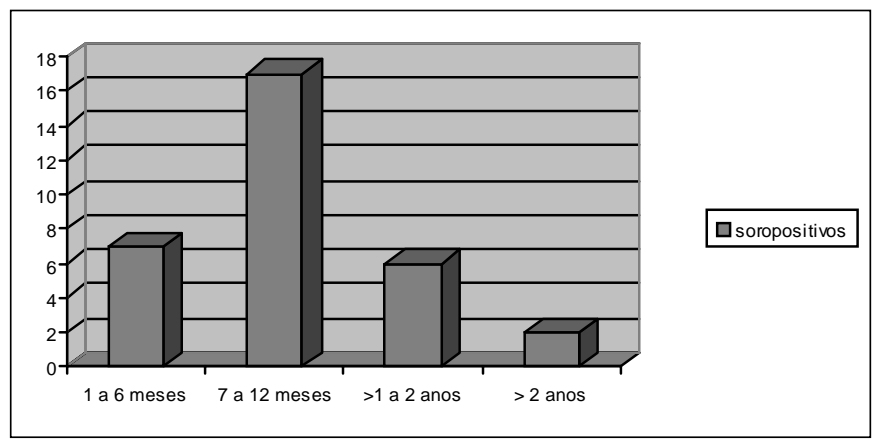

Grafico 1: Freqüência dos animais reagentes à $B$. henselae segundo sua faixa etária.

Em relação à freqüência de animais soropositivos no grupo de felinos hígidos e doentes, observou-se distribuição similar entre os grupos, sendo 17 animais $(53,1 \%)$ nos hígidos e 15 animais (46,9 \%) nos doentes. O mesmo ocorre em relação a distribuição dos reagentes a $B$. henselae de acordo com o sexo: 17 animais soropositivos entre os animais hígidos e 15 animais soropositivos entre os doentes.

\section{Discussão e conclusões}

A freqüência de felinos reagentes a $B$. henselae observada na presente amostragem, de 16\%, mostra-se semelhante à de alguns outros estudos ao redor do mundo; $12,5 \%$ nos Alpes Suíços (Glaus et al.,1997), África do Sul com 21\% (Kelly et al., 1996); porém é menor que nos EUA com 35,8\%(Foley et al., 1998); na Alemanha com 50\% (Bergmans et al., 1997), e na

\section{Referências}

ABBOTT, R. C.; CHOMEL, B. B.; KASTEN, R. W.; FLOYD-HAWKINS, K. M.; KIKUCHI, Y.; KOELER, J. E.; PEDERSEN, N. C. Experimental and Natural infection with $B$. henselae in domestic cats. Comp. Immun. Microbiol. Infect. Dis., v. 20, n. 1, p. 41-51, 1997.
Califórnia com $81 \%$ (Yamamoto et al., 1998), e maior que na Suíça e Japão, com 8,3\% (Glaus et al., 1997) e 9,1\% (Maruyama et al., 1998), respectivamente. No CCZ de São Paulo observam-se $46 \%$ dos felinos com anti- $B$. henselae (Slhessarenko et al., 1996).

Convencionou-se considerar no presente trabalho o título mínimo de 100 como o título a partir do qual os felinos foram considerados positivos (Raoult et al., 1994), o que em parte explicaria a disparidade dos diversos resultados encontrados por outros autores, assim como a escolha da amostragem utilizada e as condições de manutenção dos felinos (Bergmas et al., 1997).

A maior freqüência de reagentes observada na faixa de 7 a 12 meses encontra respaldo na literatura, segundo a qual a maioria dos casos de infecção humana por B.henselae, os gatos envolvidos com os quais os pacientes relatam contato são filhotes ou jovens, geralmente em menos de 1 ano de idade, dos quais se isolou o agente etiológico. A bacteremia por $B$. henselae que ocorre nos felinos é aparentemente de curta duração, de cerca de 1 a 4 meses (24 meses em casos excepcionais) ocorrendo a soroconversão em cerca de 2 semanas. $O$ título atinge o pico em cerca de 28 dias, após o qual apresenta declínio gradual, mantendo-se em patamares mínimos por até 2 anos.

Considerando-se o decréscimo da imunidade humoral dos filhotes ao redor de 40 dias de idade (animais sensibilizados com anticorpos) e o período de incubação de 30 dias, os felinos infectados constituem-se em potencial fonte de infecção para humanos ao redor de 3 a 4 meses de idade.

A dinâmica da infecção dos felinos por $B$. henselae permite explicar que os filhotes de 1 a 6 meses de idade já tenham anticorpos circulantes e que a freqüência máxima de reagentes tenha sido observada entre animais de 7 a 12 meses. Vale a pena ressaltar que nessa idade os animais domiciliados estão em contato íntimo com seus proprietários, geralmente crianças, aumentando grandemente a chance de mordeduras ou arranhaduras acidentais e, conseqüentemente, o aparecimento das patologias relacionadas com a DAG desde linfoadenopatias benignas até outras complicações como dores abdominais, dores de cabeça e perda de peso que requerem maiores cuidados médicos (Reynolds, MG et al., 2005, Liao HM et al., 2006).

Não há nenhuma diferença na susceptibilidade a infecção entre os sexos, sugerindo que os mesmos tenham a mesma oportunidade de contágio direto entre eles ou através de vetor, no caso a pulga (Higgins et al., 1996; Foley et al., 1998).

$\mathrm{E}$ a ausência de relação entre a doença e soropositividade à $B$. henselae observada no presente trabalho vem confirmar pouca ou nenhuma patogenicidade do agente para os gatos domésticos, como já relatados por outros autores, conferindo à Bartonella henselae maior importância ao seu hospedeiro humano do que felino (Groves et al., 1994; Chomel et al., 1995; Abbott et al., 1997).

AMARRI, S.; FUMAROLA, D.; PECE, S.; BALLI, F. Fever and hepatoesplenomegaly in two children, due to the cat scratch disease: positive serology for Afipia felis and Rochalimaea henselae. Ped. Ver. Commun. v. 82, p. 115-119, 1995. 
AMEREIN, M. P.; DE BREIL, D.; JAULHAC, B.; MEYER, P.; MONTEIL, H.; PIEMONT,Y. Diagnostic value of the indirect immunofluorescence assay in cat-scratch disease with Bartonella henselae and Afipia felis antigens. Clin. Diagn. Lab. Immunol., v. 3, n. 2 , p. 200-204, 1996.

ARLET, G.; PEROL, Y. Cat-scratch disease bacteria. New Rev Fr Hematol, v. 32, p. 461-463, 1990.

ARLET, G.; PEROL-VAUCHEZ, Y. The current status of cat-scratch disease: an update Review. Comp. Immun. Microbiol. Infect. Dis., v. 14, n. 3, p. 223-228, 1991.

BERGMANS, A. M. C.; GROTHEDE, J. W.; SCHELLEKENS, J. F. P.; VAN EMBDEN, J. D. A.; OSSEWARDDE, J. M.; SCHOULS, L. M. Etiology of cat-scaratch disease comparison of polymerase chain reaction detection of Bartonella (formely Rochalimaea) henselae and Afipia felis DNA with serology and skyn tests. J. Infect. Dis., v. 171, p. 916923, 1995.

BERGMANS, A. M. C.;PEETER, M. F.; SCHELLENKS, J. F.P.; VOS, M. C.; SABBE, L. J. M.; OSSEWARD, J. M.; VERBAK, H; HOOFT, H. J.; SCHOULS, L. M. Pitfalls and falacies of cat-scratch serology: evaluation of Bartonella henselae - basead indirect fluorescence assay and enzime-liked immunoassay. J. Clinic Microb., v. 35, n. 8, p.19311937, 1997.

BERGMANS, A. M. C.; JONG, C. M. A.; VANAMERONGEN, G.; SHOT, C. S.; SCHOULS, L. M. Prevalence of Bartonella species in domestic cats in the Netherlands. J. Clinic Microb., v. 35, n. 9, p. 2256-2261, 1997 b. BRENNER, D.; HOLLS, D. G.; MOSS, C. W. Proposal of Afipia gen nov, with Afipia felis sp nov (formerly the cat-scratch disease bacillus), Afipia clevelandensis sp nov (formerly the Cleveland Clinic Foundation Strain), Afipia broomeae sp nov, and three unnamed genospecies. J. Clinic Microb., v. 29, n. 11, p. $2450-2460,1991$.

CHOMEL, B. B.; ABBOTT, R. C.; KASTEN, R. W.; FLOYD- HAWKINS, K. A.; KASS, P. H.; GLASER, C. A.; EDERSEN, N. C.; KOELER, J. E. Bartonella henselae prevalence in domestic cats in California: risk factors and association between bacteremia and antibody titers. $J$. Clin. Microbiol., v. 33, n. 9, p. 2445-2450, 1995.

CHOMEL, B. B.; KASTEN, R. W.; FLOYD-HAWKINS, K.; CHI, B.; YAMAMOTO, K.; ROBERTS-WILSON, J.; GURFIELD, N. A.; ABBOTT, R. C.; PEDERSEN, N. C.; KOELER, J. E. Experimental transmition of Bartonella henselae by the cat flea. J. Clin. Microbiol, v. 34, n. 8, p. 1952-1956, 1996.

CHOMEL, B. B.; KASTEN, R. W.; HENN, J. B.; MOLIA, S. Bartonella infection in domestic cats and wild felids. Ann N Y Acad Sci., v. 107, n. 8. p. 410-415, 2006.

DALTON, M. J.; OBINSON, L. E.; COOPER, J.; REGNERY, R. L;OLSON, J. G.; CHILDS, J. E. Use of Bartonella antigens for serologic diagnostic of cat-scratch disease at a National Referral Center. Arch Intern. Med, v. 155, p. 1670-1676, 1995.

DRANCOURT, M.; RAOULT, D. La maladie des griffes du chat et la pathologie à Bartonella (Rochalimaea). Presse Med., v. 24, n. 3, p. 183-188, 1995.

FOLEY, J. E; CHOMEL, B.; KIKUCHI, Y:; YAMAMOTO, K.; PEDERSEN, N. $C$. Seroprevalence of $B$. henselae in cattery cats: association with cattery hygiene and flea infestation. Vet $Q$, v. 20, n. 1, 1998.

GLAUS, T.; HOFMANN-LEHMANN, R.; GREENE, C.; GLAUS, B.; WOLFENSBERGER, C.; LUTH, H. Seroprevalence of Bartonella henselae infection and correlation with disease status in cats in Switzerland. J. Clin. Microbiol, v. 35, n. 11, p. 2883-2885, 1997.

GREENE, C.E.;McDERMOTT,M.;JAMESON,P.H.;ATKINS, C. L.;MARKS, A. M. Bartonella henselae infection in cats: evaluation during primary infection, treatment, and rechallenge infection. J. Clin. Microbiol., v. 34, n. 7 , p. 1682-1685, 1996.

GROVES, M. G.; HARRINGTON, K. S. Rochalimaea henselaeinfectons - New recognized zoonoses tronsmitted by domestic cats. Leading Edge of Medicine- Review- J.Amer.Vet. Med. Ass. v. 204, n. 2, p. 267$371,1994$.
KELLY, P. J.; MATHEWMAN, L. A.; HAYER, D.; DOWNEY, S.; WRAY, K.; BRYSON, N. R., RAOULT, D. Bartonella (Rochalimaea) henselae in Southern Africa - evidence for infections in domestic cats implications for veterinarians. S. Afr. Vet. Med. Assoc., v. 67, n. 4, p. 182-187, 1996.

KIRKPATRICK, C. E.; GLICKMAN, L. T. Cat-scratch disease and a role of the domestic cat: Vector, Reservoir, or Victim? Med. Hyp., v. 28, n. 2, p. 145-149, 1989.

KORDICK, D. L.; BREITSCHWERDT, E. B. Relapsing bacteremia after blood transmission of $B$. henselae to cats. Am. J. Vet. Res., v .58, n. 5, p. 492-497, 1997.

KORDIC, D. L.; BREITSCHWERDT, E. B. Persistent infection of pets within a householt with three Bartonella species. Emer. Infect.s Dis., v. 4, n. 2, p. 325-328, 1998.

LAMPS, L. W.; SCOTT, M. A. Cat-scratch disease: historic, clinical, and pathologic perspectives. Am. J. Clin. Pathol., v. 121, suppl: S71-80, 2004.

LIAO, H. M.; HUANG, F. Y.; CHI, H.; WANG, N. L.; CHEN, B. F. Systemic cat-scratch disease - J. Formos. Med. Assoc. v. 105, n. 8, p. 674679, 2006.

MARGILETH, A. M.; HAYDEN, G. F. Cat-scratch disease from feline affection to human affection. N. Engl. J. Med., v. 329, n. 1, p. 53-54, 1993.

MIKOLAJCZYK, M. G.; O'REILLY, K. L. Clinical disease in kittens inoculated with a pathogenic strain of Bartonella hensellae. Am. J. Vet. Res., v. 61, n. 4, p. 375-379, 2000.

RAOULT, D.; DUPON, H. T.; ENEA-MUTILLOD, M. Positive predictive value of Rochalimaea henselae antibodies in the diagnosis of catscratch disease. Clin. Infect. Dis., v. 19, n. 2 , p. 355, 1994.

REGNERY, R. I.; OLSON, J. G.; PERKINS B.; BIBB, W. Serological response to "Rochalimaea henselae" antigen in suspected cat-scratch disease. Lancet, v. 33, n. 9, p. 1443-1445, 1992.

REGNERY, R. L.; ROONEY, J. Á.; JOHNSON, A. M.; NESBY, S. L.; MANZEWITSCH, P.; FEAVER, K.; OLSON, J. G. Experimentally induced Bartonella henselae infections followed by challenge exposure and antimicrobial therapy in cats. Am. J. Vet. Res., v. 57, n. 12, p. 17141719, 1996.

REYNOLDS, M. G.; HOLMAN, R. C.; CURNS, A. T.; O'REILLY, M.; McQUISTON, J. H.; STEINER, C. A. Epidemiology of cat-scratch disease hospitalizations among children in United Estates. Pediatr. Infect. Dis. J. v. 24, n. 8, p. 700-704, 2005.

SLHESSARENKO, N.; OLIVEIRA CAMARGO, M. C. G.; D'AURIA, S. R. N.; MOUREIZ, E. S. M.; CAMARGO, M. E. Soroprevalência de B. henselae em gatos do município de São Paulo. Revista da Sociedade de Medicina Tropical, n. 28, 1996, suplemento 1. (Apresentado no XXXII Congresso do SBMT).

TOMPKINS, D. C.; STEIGBIGEL, R. T. Rochalimaea's role in Cat-scratch disease and Bacillary Angiomatosis. Annals of Internal Medicine, v. 118, n. 5, p. 388-389, 1993.

UENO, H.; HOHDATSU, T.; MURAMATSU, Y.; KOYAMA,H; MORITA, C. Does coinfection of Bartonella henselae and FIV induce clinical disorders in cats? Microbiol. Immunol., v. 40, n. 9, p. 617-20, 1996.

WELCH, D. F.; SAN JOAQUIN, V.; SLATER, L. Bartonella henselae: etiology of hepatic cat scratch disease. C. Samp Am. Soc. Clin. Pat., MB 96-7 (MB-258), v. 39, p.102-113, 1996 (Microbiology).

YAMAMOTO, K.; CHOMEL, B. B.; LOWENSTINE, L. J.; KIKUCHI, Y.; PHILLIP, L. G.; BARR, B. C., SWIFT, P. K.; JONES, K. R.; RILEY, S. P.; KASTEN, R. W.; FOLEY, J. E.; PEDERSEN, N. C. Bartonella henselae antibidy prevalence in free-ranging and captive wild felids from California. J.Wild., v. 34, n. 1, p. 56-63, 1998.

ZBINDEN, R. Bartonella henselae-based indirect fluorescence assays are useful for diagnosis of cat-scratch disease. J. Clin. Microbiol., v. 36, n. 12, p. 3741-3742, 1998. 